\title{
XXVI. Case of hydrocele, improperly treated as rupture
}

\section{John Taunton Esq.}

To cite this article: John Taunton Esq. (1810) XXVI. Case of hydrocele, improperly treated as rupture, Philosophical Magazine Series 1, 36:148, 151-152, DOI: $\underline{10.1080 / 14786441008563157}$

To link to this article: http://dx.doi.org/10.1080/14786441008563157

曲 Published online: 18 May 2009.

Submit your article to this journal $\llbracket$

Џll Article views: 2

Q View related articles ¿ 


\section{$\left[\begin{array}{ll}151 & ]\end{array}\right.$}

XXVI. Case of Hydrocele, improperly treated as Rupture. By Jorn Taunton, Esq., Surgeon to the City and Finsbury Dispensaries, and to the City Truss Society for the Relief of the Ruplured Poor.

\section{To Mr. Tilloch.}

SIR, $I_{T}$ is not the least of the evils which accompany a state of disease among the poorer classes of this large metropolis, that their complaints are frequently misunderstood, and consequently treated in a manner which tends to increase rather than to alleviate their sufferings. The superficial and hasty view which is but too often taken, even by regular medical practitioners, of the diseased victim of poverty on the one hand, and the allurements held out by mercenary and ignorant pretenders to medical skill on the other, are the causes of this additional affiction to the poor.

Those who officiate as medical officers to the numerous public charities which do honour to this great city, have daily opportunities of witnessing the melancholy effects of the errors thus committed. The following case of this kind, which occurred lately uuder my own inspection, and which had nearly terminated fatally to the patient, is one of the many illustrations of this observation which may be adduced.

Thomas Erskine, æt. 53, servant to Mr. Thomas Butcher, of Charing Cross, a few years aro received a kick in the scrotum, which occasioned a swelling, and which has continued ever since. Ai first it was attended with extreme pain ; but this soon ceased, and the tnmonr assumed an indurated appearance. The poor man applied to two regular surgeons in his immediate neighbourhood, who informed him that his complaint was a rupture, and recommended a truss. Attracted by an alluring advertisement from some truss-makers in Solio, the patient applied to them: these gentlemen, after examining the paitent, and affecting a great deal of medical and anatomical knowledge, confirmed the opinion of the surgcons, and applied a truss to the tumour, for which they charged the exorbitant price of a guinea. This happened three ycars ago, and the patient has ever since worn the instrument thus applied, with more or less inconvenience. A few weeks ago he was admitted a patient at the City Dispensary, when on examining him I found the case to be a dccided hydrocele. The operation of tapping was immediately performed, and the patient in

$$
\mathrm{K} 4
$$


a few days was restored to his former state of health. Pilula rbei cum terebinth. formed the only prescription which I found necessary to administer.

Greville Street, Hatton-Garden, I am, \&c. August 24, 1810.

John Taunton.

XXVII. Proceedings of Learned Societies.

\section{ROYAL SOCIETY.}

ThE experiments detailed in Mr. Davy's paper respecting the muriatic acid, of which we gave a brief report in our last Number, are so bighly interesting, that no apology can be necessary for again bringing the subject before our readers, and endeavouring to present the results in a concise yet perspicuous form. But before proceeding to this, we must beg our readers to correct two typograpbical errors in our last report. In page 71, line 20, for "nine modes," read nice modes; and in line 22, for " nine deductions," read some deductions.

The conclusions drawn by Mr. Davy from the series of facts with which this valuable paper is enriched, will serve to extend and enlighten the theory of chemistry to even a greater extent than any of the brilliant discoveries formerly made by this indefatigable philosopher. The following are the conclusions to which we allude :-

1st. The oxymuriatic acid is (as far as our knowledge extends) a simple sullstance, which may be classed in the same order of natural bodlies as oxygen gas; being determined like oxygen to the pusitive surface in Voltaic combinations, and like oxygen, combining with inflammable substances, producing heat and light.

2dly. That its combinations with inflammable bodies are analogous to oxides and acids in their properties, and powers of combination, but they differ from them in being for the most part decomposable by water.

3 dly. That hydrogen is the basis of the muriatic acid, and oxymuriatic acid its acidifying principle.

4thly. That the compounds of phosphorus, arsenic, tin, Sce, with oxymuriatic acid, approach in their nature to aciás, and neutralize ammonia and other salifiable bases.

5thly That the combination of ammonia with phosphorus acictified by oxymuriatic acid is a peculiar compound, having properties like those of an earth, and is not deconposable at an intense red heat.

6thly. 